\title{
CDISC Shared Health And Research Electronic Library
}

National Cancer Institute

\section{Source}

National Cancer Institute. CDISC Shared Health And Research Electronic Library. NCI

Thesaurus. Code C142415.

A global, accessible electronic library that enables precise and standardized data element definitions to be used within applications and across studies to improve biomedical research and its link with healthcare. (CDISC) 